\title{
SUSPENSION BY REGULAR AND GROUPY WAVES OVER BEDFORMS IN A LARGE WAVE FLUME (SISTEX99)
}

\author{
C.E. Vincent ${ }^{1}$ M.ASCE, D.M. Hanes ${ }^{2}$ M.ASCE, C. M. Dohmen-Janssen ${ }^{3}$, G. \\ Klopman $^{4}$, S.R. McLean ${ }^{5}$ M.ASCE, C. Obhrai ${ }^{1}$ and J.S. Ribberink ${ }^{3}$
}

Abstract: Suspended sand concentrations and bedforms under waves were measured in the controlled environment of a large wave flume. Three suspension conditions are discussed here; those occurring with regular (monochromatic) waves of height $0.55 \mathrm{~m}$ over anorbital ripples, regular waves $1.0 \mathrm{~m}$ high over orbital bedforms, and repeating wave groups (with a significant wave height of $0.6 \mathrm{~m}$ ) also over orbital-scale features. In all cases the wave-towave variability in suspended load was high $(\sim 30 \%)$. Patterns of suspension were dependent on the bedform type and on instrument location relative to the bedform. Regular waves suspended an order of magnitude more sediment than groupy waves with a similar significant wave height illustrating the importance of sequences of high waves in pumping-up sediment concentration into the water column.

\section{INTRODUCTION}

Bedforms are known to influence the suspension of sand from the seabed. Vincent et al. (1991) noted non-linear changes in sand suspension during a storm and suggested that these were due to flattening of the bed forms by the largest waves at the height of the storm. Bedform evolution in response to waves also depends on the regularity of the forcing; Nielsen (1981) noted the difference in the scales of bedforms depending on whether the waves were laboratory (i.e. regular waves with a clearly defined wavelength)

1 University of East Anglia, School of Environmental Sciences, Norwich NR4 7TJ, UK,

2 University of Florida, Dept. of Civil and Coastal Eng., PO Box 116590, Gainesville, FL 326116590, USA

3 University of Twente, Dept. of Civil Eng., PO Box 217, 7500 AE Enschede, The Netherlands.

4 Albatros Flow Research, POBox 85, 8325 Vollenhove, The Netherlands

5 University of California, Mechanical and Environmental Engineering, Santa Barbara, CA 93106, USA, 
or field where the spectral width was large and the wavelength variable. Wave groups produce suspensions that tend to lag the largest waves in the group as sand is pumped-up through the water column by successive waves (Hanes 1991; Villard et al. 1999). In a series of flume experiments using prototype-scale waves over a sand bed we investigate the suspension of sand and the evolution of the bedforms by regular and groupy waves.

\section{THE EXPERIMENT}

The Experiment A series of experiments were conducted in the $300 \mathrm{~m}$-long wave flume at the Forschungs Zentrum Kuste (FZK) in Hannover, Germany where prototype-scale waves can be generated using a 2-segment computer-controlled wave generator (Ribberink et al. 2000). A sand bed $45 \mathrm{~m}$ long and $0.7 \mathrm{~m}$ thick was installed in the flume $\sim 100 \mathrm{~m}$ from the wave generator. The sand used was well-sorted quartz sand with a $\mathrm{D}_{50}$ of $0.230 \mathrm{~mm}$ and a fall velocity of $0.031 \mathrm{~ms}^{-1}$ (Van Rijn 1984) but there was also a small proportion of mud that prevented video or any other optical measurements and that produced a small background signal for the acoustic instrumentation. The measurements presented here are from a 2.4m-long multiple transducer array (MTA) (Hanes et al. 1998), an acoustic backscatter (ABS) system (2, 4, $5 \mathrm{MHz}$ ) mounted close to the MTA, a two-component Valeport discus-head electromagnetic current meter $(\mathrm{emcm})$ at $70 \mathrm{~cm}$ and a resistance wave-wire. The instruments were cantilevered out $1 \mathrm{~m}$ from the flume wall close to the middle of the sand bed. The suspended sand concentrations shown here are from the $2 \mathrm{MHz}$ ABS transducer, chosen because it was the least sensitive to the mud in suspension (the other transducers available were at 4 and $5.5 \mathrm{MHz}$ ) and the acoustic attenuation by the sediment was much less. Typical background values due to the mud (determined by taking backscattered measurements immediately waves had stopped) were equivalent $0.001-0.010 \mathrm{kgm}^{-3}$ of the $0.230 \mathrm{~mm}$ sand. ABS profiles were recorded at $\sim 3 \mathrm{~Hz}$, each recorded profile being the average of the backscatter from 12 acoustic 'pings'. 2048 ABS profiles were recorded in each 'Burst' and lasted 10 minutes.

A number a different wave and bed conditions were used in the flume, regular (monochromatic), repeating groups and natural waves from field experiments at Duck, N Carolina. For the regular and repeating groups wave periods of 6.5 and 9.1s were used; these periods were chosen to be the same as the periods used by (Ribberink and Al-Salem $1995)$ in the Delft oscillating wave tunnel. Wave heights of between $0.55 \mathrm{~m}$ and $1.6 \mathrm{~m}$ $\left(\mathrm{H}_{\mathrm{m} 0}\right)$ were generated, with water depths over the sand bed of 3 to $3.75 \mathrm{~m}$ which produced a variety of bed configuration varying from small anorbital, through large orbital bedforms to flat-bed sheet-flow conditions. In general wave were of a particular height and period were generated for two sequential 30-minute runs; the first run was designed to allow the sand bed to come into equilibrium with the waves while the second run was for measurements of the equilibrium suspension. In this paper we present details of the relationship between the suspended sand concentration profiles and wave and bed conditions for two regular wave conditions and one repeating wave group; all three have a wave period of $6.5 \mathrm{~s}$ and a water depth of $3.75 \mathrm{~m}$. 


\section{RESULTS}

The first waves to be generated in the flume after the sand bed had been prepared, raked flat and the flume filled, were regular waves with a design height of $0.55 \mathrm{~m}$. A norbital ripples ( $\mathrm{M}$ iller and Komar 1980) with a wavelength of $\sim 0.2 \mathrm{~m}$ and heights between $0.5-2 \mathrm{~cm}$ evolved rapidly (Table 1 ). These were followed by larger regular waves, $1.0 \mathrm{~m}$ in height. The bedforms rapidly responded to the waves (within around 100 waves) changing from the small anorbital ripples to approximately orbital features that scaled with the orbital excursion $D_{0}$, consistent with bedform wavelength $\lambda_{b}=0.6 D_{0}$ (M iller and Komar 1980).

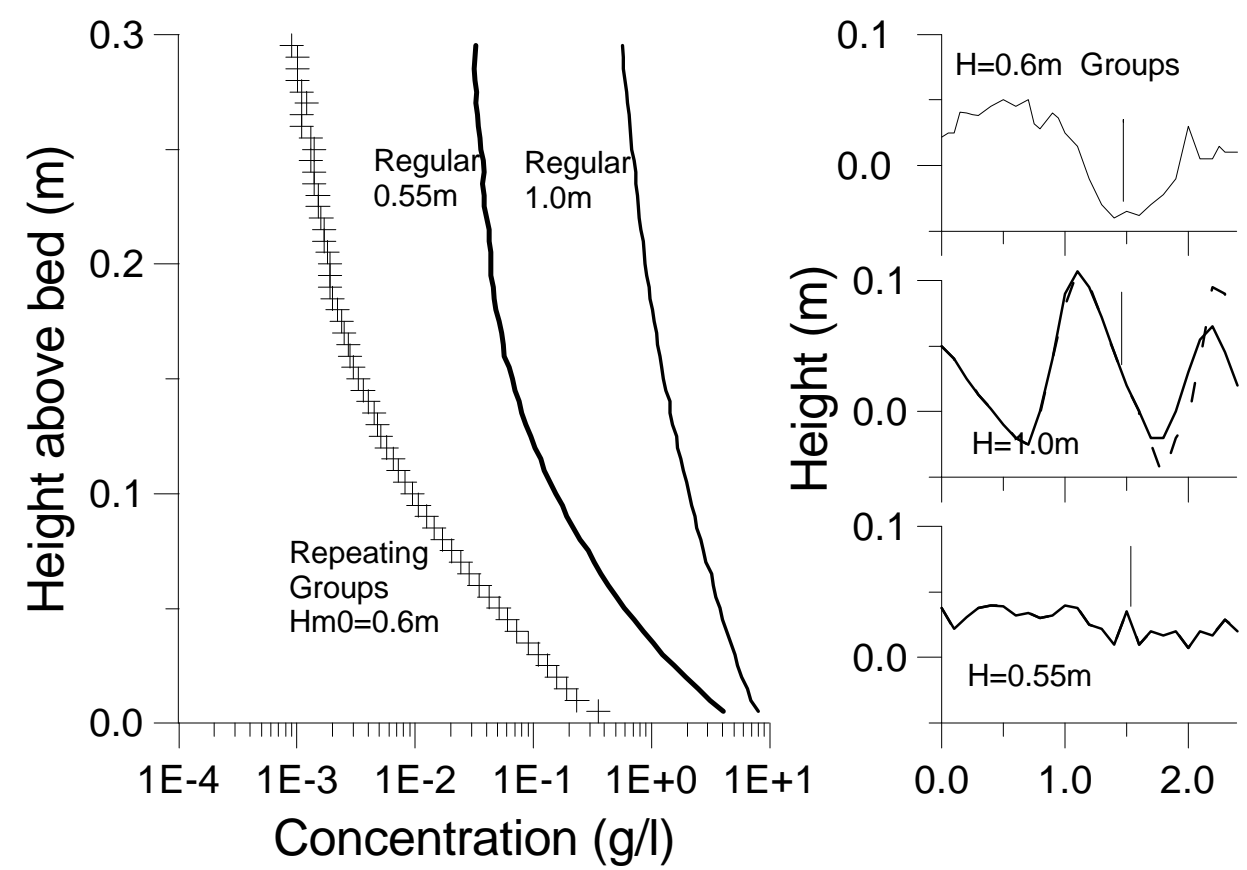

Figure 1 Run-averaged suspended sand concentration profiles from the ABS and bedforms from the MTA

The suspended sand concentration profiles (averaged over 10 minutes) show considerable differences. Suspension by $1.0 \mathrm{~m}$ waves (M A A) over the large bedforms is more than 5 -times that suspended by the $0.55 \mathrm{~m}$ waves over the small anorbital ripples (figure 2). The groupy waves, despite having a significant wave height that was greater than the $0.55 \mathrm{~m}$ regular waves suspends an order of magnitude less sand (figure 1). These profiles have been calculated assuming that the size of the sand in suspension is equal to that of the bulk bed sample $(0.230 \mathrm{~mm})$ but size analysis of pump-samples taken in the centre of the tank showed that the size in suspension was $\sim 0.20 \mathrm{~mm}$ and also that it decreased with distance from the bed (typically from $0.21 \mathrm{~mm} 1-2 \mathrm{~cm}$ above the bed to $0.19 \mathrm{~mm}$ at $10 \mathrm{~cm}$ above the bed) 
Table 1 Heights, orbital excursions, bedform dimensions and suspended concentrations for the three wave conditions described.

\begin{tabular}{|c|c|c|c|c|c|c|}
\hline \multirow[t]{2}{*}{ Wave type } & \multirow{2}{*}{$\begin{array}{c}\text { Height } \\
\mathrm{m}\end{array}$} & \multirow{2}{*}{$\begin{array}{c}\text { Orbital } \\
\text { Excursion m }\end{array}$} & \multicolumn{2}{|c|}{ Bedforms dimensions } & \multicolumn{2}{|c|}{ Concentration $\mathrm{kgm}^{-3}$} \\
\hline & & & Height & Length & $2 \mathrm{~cm}$ asb & $20 \mathrm{~cm}$ asb \\
\hline Regular & 0.55 & 0.82 & $0.5-2 \mathrm{~cm}$ & $20 \mathrm{~cm}$ & 2.0 & 0.043 \\
\hline Regular & 1.0 & 1.48 & $15 \mathrm{~cm}$ & $1.0-1.5 \mathrm{~m}$ & 5.8 & 0.88 \\
\hline $\begin{array}{l}\text { Repeating } \\
\text { Groups }\end{array}$ & 0.6 & 0.92 & $\begin{array}{c}8 \mathrm{~cm} \\
1-2 \mathrm{~cm}\end{array}$ & $\begin{array}{c}2 \mathrm{~m} \\
0.2-0.4 \mathrm{~cm}\end{array}$ & 0.16 & 0.0019 \\
\hline
\end{tabular}
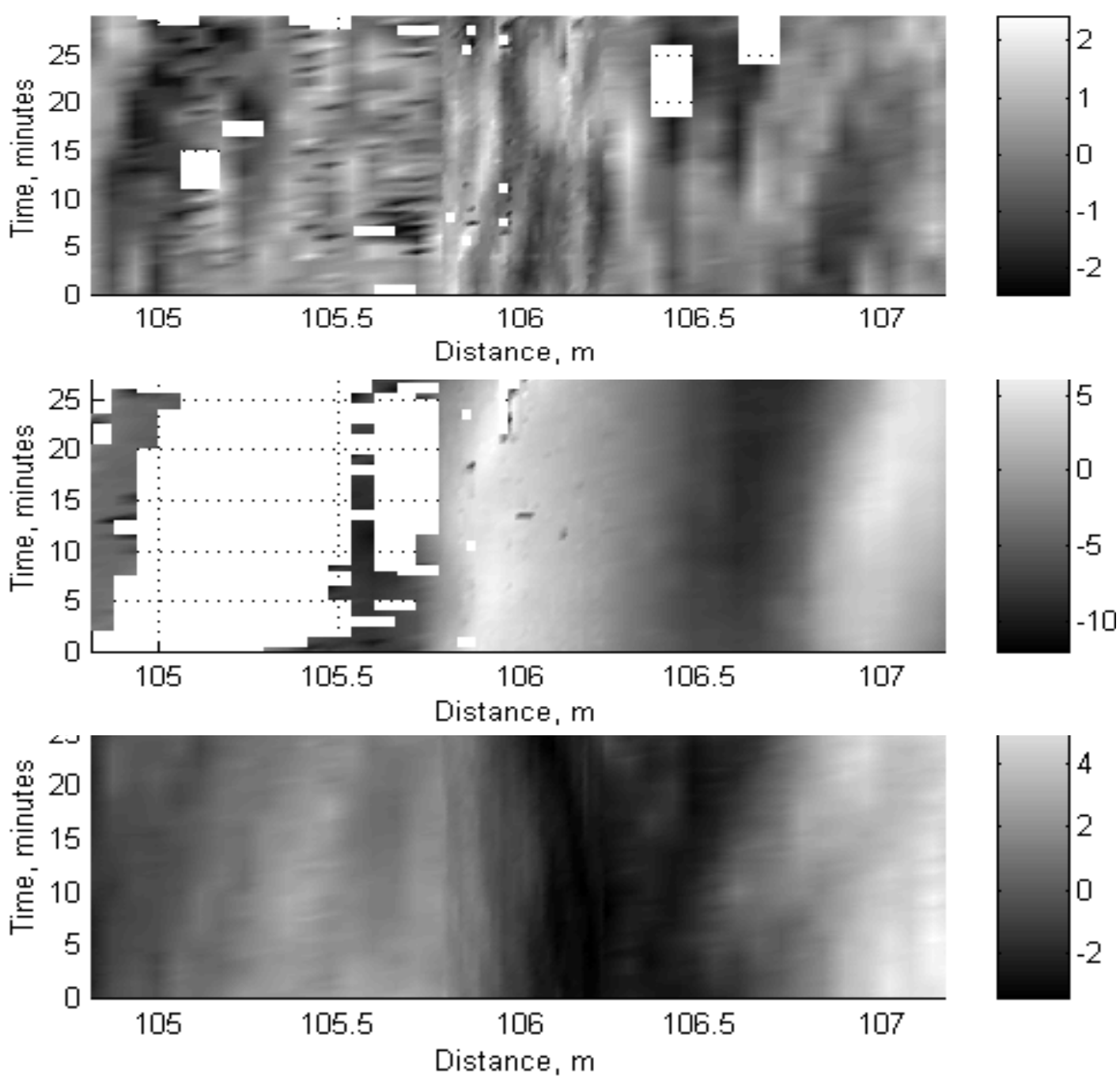

Figure 2 Bedform profiles and their temporal changes measured by the MTA, for $0.55 \mathrm{~m}$ regular waves (top), $1.0 \mathrm{~m}$ regular waves (centre), $0.6 \mathrm{~m}$ repeating groups (bottom). The colorbar scale is in centimeters. Distances are measured from the wave generator with the ABS at $106.2 \mathrm{~m}$. Note the three sections of the MTA; in the centre there are 32 transducers $1.5 \mathrm{~cm}$ apart, with 16 transducers $6 \mathrm{~cm}$ apart of either side. Blanks show areas with no good data

\section{Regular Waves, $0.55 \mathrm{~m}$ over anorbital ripples}


The suspension of sand as the $0.55 \mathrm{~m}$ regular waves begin is shown in figure 3 . The horizontal current profile has been superimposed to indicate the times of the wave cycle at which the suspension occurs. Little suspension occurs for the first two waves. The total suspended load was calculated using a bed-location defined from the Burstaveraged concentration profile using the 'break-in-slope' to identify the first acoustic measurement above the bed that was uncontaminated by backscatter from the bed (see figure 4b). The time history of the total suspended load (integrating the concentration profiles from the bed to $+0.3 \mathrm{~m}$ ) over 10 minutes shows an apparent 5 -fold increase during the Burst (figure 4a). Examination of sections of the Burst shows that this increase in suspended load is due to changes in the bed position as bedforms migrate beneath the ABS (figure 4b); when the total load is adjusted for the varying bedposition the total load variation loses its time dependance. However this indicates how important it is to include the temporal changes in the sea-bed in ABS measurements; the bed position cannot be assumed to be constant.

Figure 3 Suspended sand concentration profiles (on a log-scale, white $>10 \mathrm{kgm}^{-3}$, black $<1 \mathrm{kgm}^{-3}$ ) with horizontal current seed superimposed in white to show phase relationships.

In comparison to the field this flume experiment is highly controlled yet it is clear from figure a that the suspension varies considerably from wave to wave; for the time period $50-250 \mathrm{~s}$, the variance of the total suspended load is $30 \%$ of the mean. In figure 5 we have plotted the first 100s of the total suspended load time-series (the same time period as shown in figure 2) together with the horizontal current and the surface elevation from the wave-wire. The total load lags the current at the wave-crest by around $0.5 \mathrm{~s}$ but with little suspension occurring during the wave trough; this is surprising in view of the lack of wave-asymmetry (maximum currents in the troughs are $95 \%$ of those under the crests) and that the ripple-wavelength is small compared to the orbital excursion.

To reduce the influence of the wave-to-wave variability the suspension profiles have been averaged according to the phase of the wave. The grey-scale diagram in figure 6a, average for 25 waves centred on $t=125 \mathrm{~s}$, shows the sand being suspended from the seabed exactly in-phase with the current, but with a time-lag as the sand is mixed away from the bed. The time-height relationship of maximum concentrations indicates a vertical speed of $23 \pm 1.5 \mathrm{mms}^{-1}$. This confirms that the highest suspension was occurring under the wave crest relative to the trough. However later in the same burst (figure 6b, 25waves centred on $\mathrm{t}=500 \mathrm{~s}$ ) shows the suspension is reversed; more suspension from under the wave 
trough. Even with anorbital ripples position relative to the bedform does influence the measured suspension pattern.

Figure 4a (left) Total (vertically-integrated) suspended load based on Burst-mean bed location. 4b (right) Average suspended sand profiles for period 150-250s (circles) and 450-550s (crosses) showing the effect of a $5 \mathrm{~mm}$ change in bed location (note change in break-in-slope position).

Figure 5 Total load variation with horizontal current speed showing the peak just after the current maximum under the wave crest (full-scale for the total load is $0.5 \mathrm{kgm}^{-2}$ ). Note the low suspension under the wave trough.

\section{Regular Waves, 1.0m over orbital ripples}

The characteristics of the suspension by the larger regular waves are different both qualitatively and quantitatively from those above. As expected, more sand is suspended and it is also lifted higher into the water column (figure 1). The ABS sensor is positioned over the stoss-slope of the bedform that migrates shorewards (in the direction of wave propagation). The bed location changes by $4 \mathrm{~cm}$ during the 10 -minute ABS Burst discussed here; the suspension patterns and concentration profiles are adjusted to account for the changing bed position

The total suspended load and the horizontal component of the current velocity for the first 100s of the Burst MAA are shown in figure 7. It is immediately clear that peaks in suspension are associated with the wave troughs not the crests. Variability in the suspension from wave-to-wave is also high; the standard deviation of the wave-average total suspended load is $\pm 31 \%$ of the mean value. With large anorbital bedforms we expect 
that the precise measurement position will have a dominant influence on the phaserelationship between the suspension and the wave, assuming that the classical picture of vortex roll-up followed by vortex ejection is applicable.

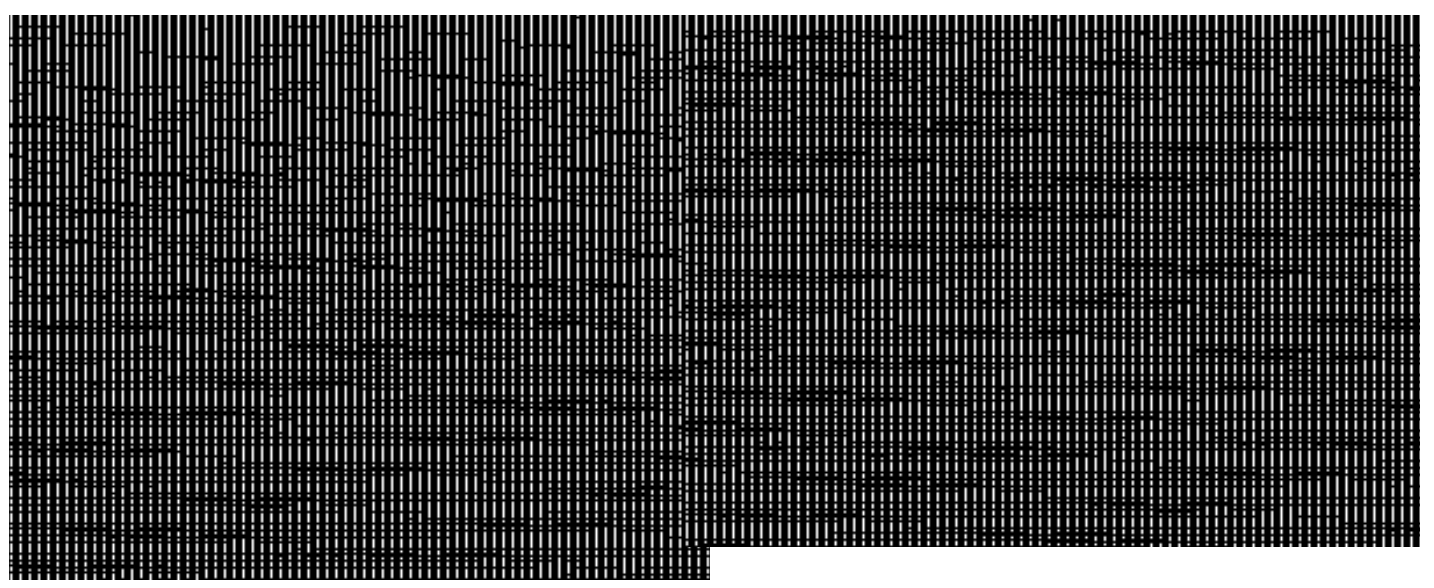

Figure $6 \mathrm{a}$ (left). Sand suspension pattern for 25 waves centred on $\mathrm{t}=125 \mathrm{~s}$. $6 \mathrm{~b}$ for 25 waves centred on $\mathrm{t}=500 \mathrm{~s}$, Current profiles are below. Horizontal scale in units of 2 . Concentrations in $\mathrm{kgm}^{-3}$.

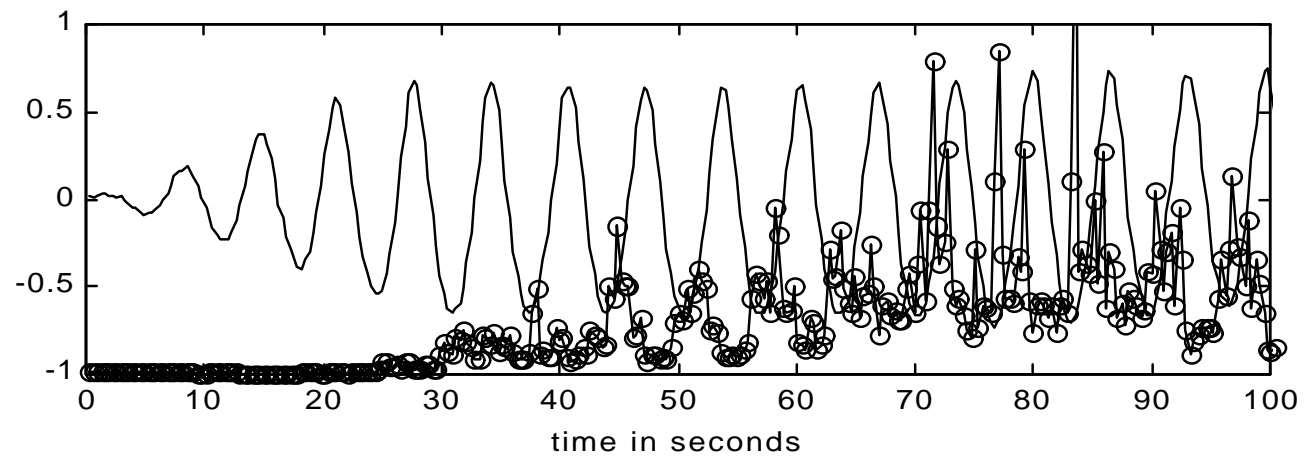

Figure 7 Total load variation (circles) and horizontal current speed (full-scale for the total load is $2 \mathrm{kgm}^{-2}$ ).

The average pattern of suspension in terms of the phase of the wave has been calculated for two periods during the burst, each of 25 waves duration centred at the beginning and end of the burst (figure 8). The patterns differ in the timing at which the suspension occurs; for the first period peaks occur just before the wave crest and just after the wave trough while for the second period the main suspension event is just after the trough. The suspension pattern is controlled by the time at which the sediment clouds associated with the vortices are swept through the beam. And this will alter as the bedform moves beneath the ABS. The MTA bedform profiles indicate a migration rate of $2-3 \mathrm{~mm} / \mathrm{min}$. 


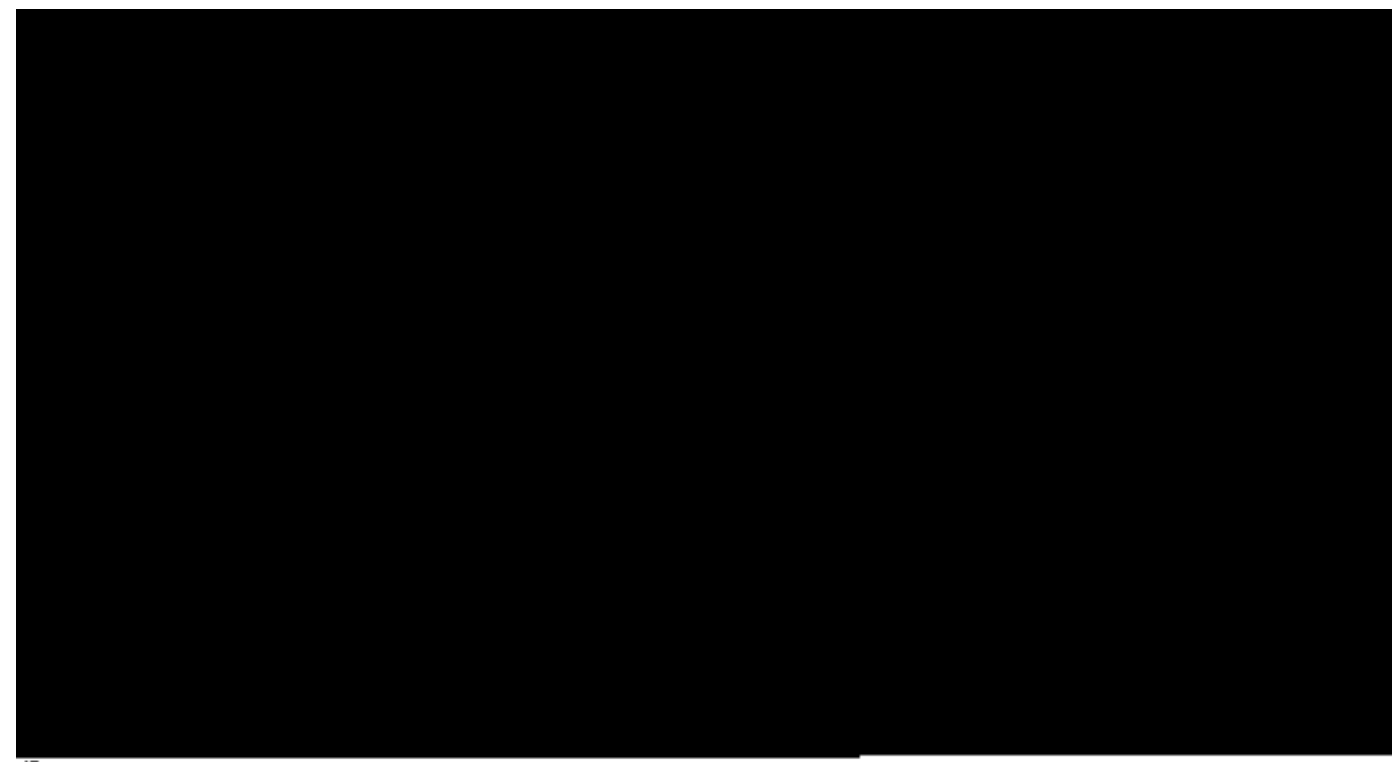

Figure $8 \mathrm{a}$ (left). Sand suspension pattern for 25 waves centred on $\mathrm{t}=125 \mathrm{~s} .8 \mathrm{~b}$ for 25 waves centred on $\mathrm{t}=500 \mathrm{~s}$, Current profiles are below. Horizontal scale in units of 2 . Concentrations in $\mathrm{kgm}^{-3}$.

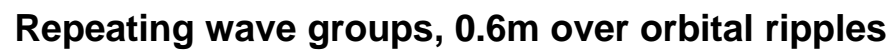

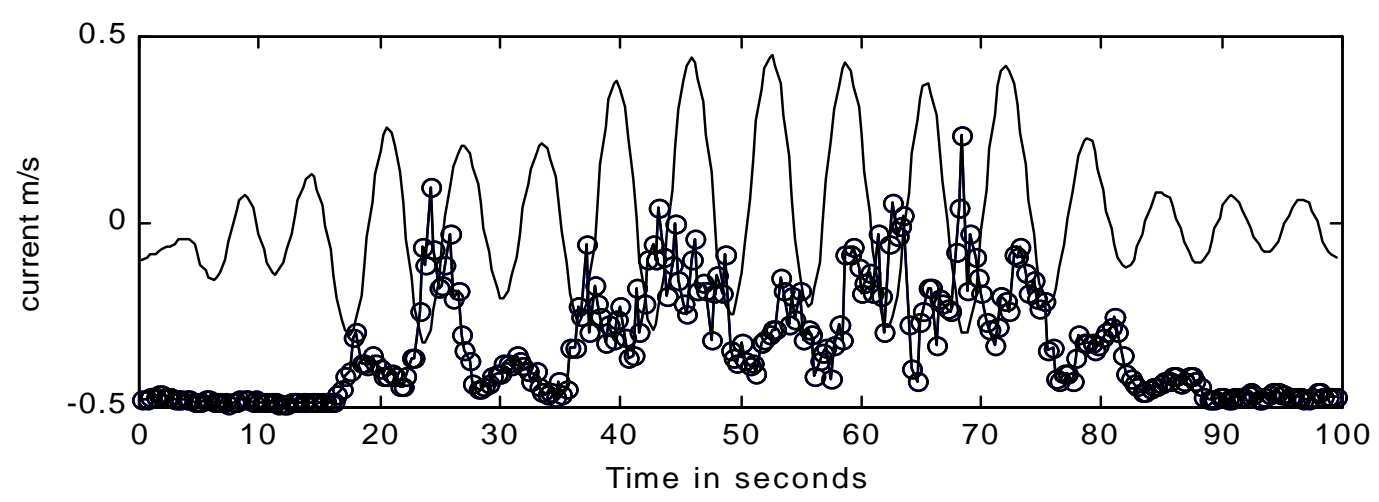

As shown in Figure 1 the most striking difference between the suspension occurring with the regular $0.55 \mathrm{~m}$ waves and the repeating groups is how little sand is suspended by the repeating groups. Figure $x x$ shows the patterns of suspension during the passage of the wave group, averaged over 5 sequential groups. Note that concentrations in this figure are shown on a log-scale. The variability in suspended load between groups is similar to the other wave conditions (variability between equivalent waves in the group) and is $\sim 30 \%$. Suspension is dominantly from the currents in the wave troughs, confirmed by the vertically-integrated suspended loads shown in figure yy. The bedforms are complex during this Run, a combination of anorbital and orbital features suggesting that the suspension pattern will also show features that are dependent on the position of the ABS relative to the bedforms. The 
suspension above $0.15 \mathrm{~m}$ lags the wave field by several waves (see the suspension around 30-40s and 70-90s) as the sediment is pumped-up higher into the water column. The high concentrations above $0.1 \mathrm{~m}$ between $70-90 \mathrm{~s}$ are similar to those described by Villard et al. (2000) for wave groups in the large wave flume in Ottawa (the bedforms in Villard's tank were small, anorbital features).

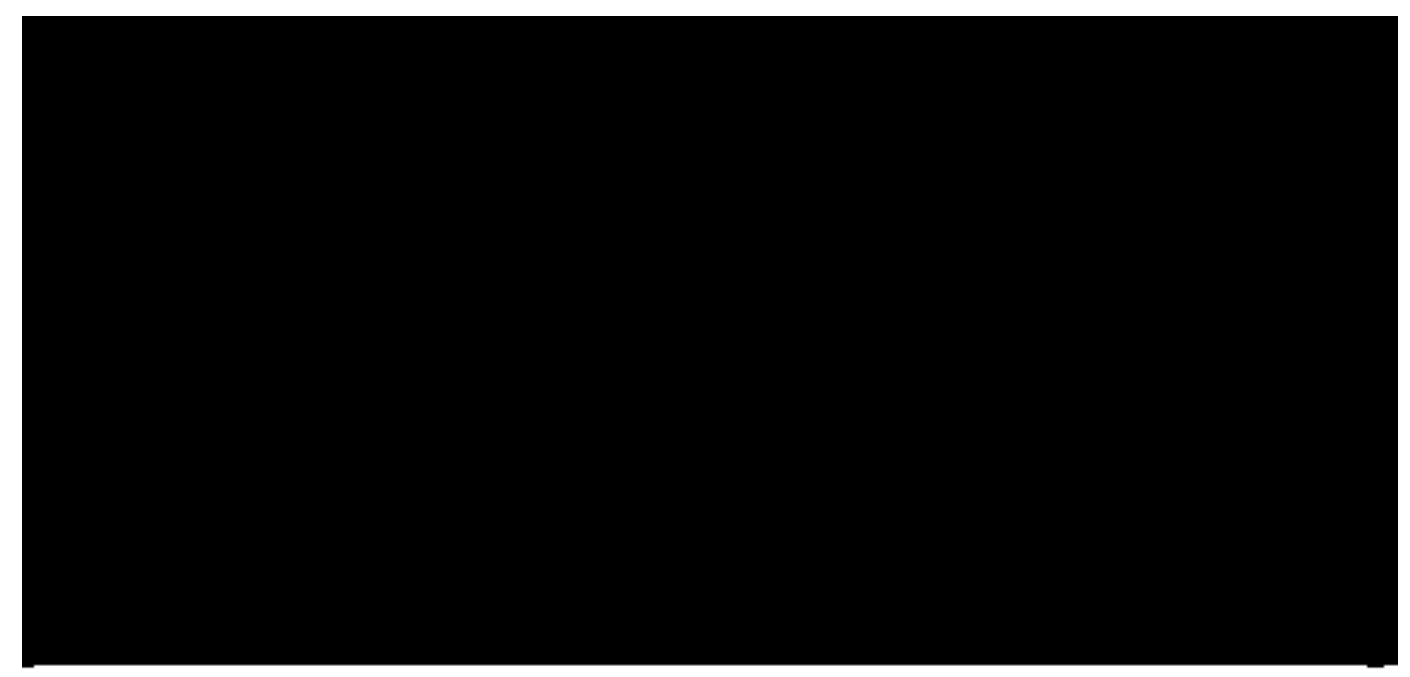

\section{DISCUSSION AND CONCLUSIONS}

The variability in the suspended load from wave-to-wave, under these highly controlled conditions, is surprising but we believe that it is real and not an artifact of the measurement technique (configurational noise left from not averaging enough acoustic pulses). We guess that we would find correspondingly large variations in turbulence intensity but it is not clear why the turbulence should vary so much, other than it is the nature of turbulence to be random. For larger bedforms the patterns of suspension are highly dependent of the precise measurement position relative to the bedform. This emphasises two important general points concerning sand transport estimation from measurements at one point a) a knowledge of type of bedforms and b) measurement location relative to anorbital are essential. A lso for acoustic systems where the bed produces a strong echo, the exact knowledge of the bed position to within a centimetre will be important for correct suspended load determination. With mobile bedforms it will generally not be sufficient to assume that the bed position will remain constant for more than a couple of minutes.

The difference between the concentrations under groupy waves versus regular waves of the similar significant wave height indicates that significant wave height alone is not going to be a good predictor of suspended load. Sequences of wave suspend more sediment, or more precisely, accumulate levels of turbulence in the water column that can 
maintain sediment in suspension. The spectral width of the wave field may be a useful parameter here, the more "groupy" the waves the higher the suspension; regular waves suspend the most sediment as they are one end-member of possible spectral widths, and can be considered as an group of infinite length.

\section{ACKNOWLEDGEMENTS}

The SISTEX 99 programme was supported by the EU M AST-III project SEDM OC, the US Office of Naval Research NICOP program, the UK Natural Environment Research Council and by the University of Hannover and FZK through the Human Capital and Mobility Program of the EU.

\section{REFERENCES}

Hanes, D. M. (1991). "Suspension of sand due to wave groups." Journal of Geophysical Research, 96(C5), 8911-8915.

Hanes, D. M., Chang, Y.-S., Conner, C. S., Jette, C. D., Thorsteson, E. D., and Vincent, C. E. "Field Observations of small scale sedimentation processes." Proceedings of the 26th Coastal Engineering Conference, Copenhagen, 88-89.

Miller, M. C., and Komar, P. D. (1980a). "Oscillation sand ripples generated by laboratory apparatus.” Jour. Sed. Pet., 50(1), 173-182.

Nielsen, P. (1981). "Dynamics and geometry of wave-generated ripples." Journal of Geophysical Research, 86(C7),, 6467-6472.

Ribberink, J. S., and Al-Salem, A. A. (1995). "Sheet-flow and suspension in oscillatory boundary layers." Coastal Engineering, 25, 205-225.

Ribberink, J. S., Dohmen-Janssen, C. M., Hanes, D. M., McLean, S. R., A.Taylor, J., and Vincent, C. E. "Near-bed sand transport mechanisms under waves: large-scale flume experiments." 26th International Coastal Engineering Conference, Sydney.

Van Rijn, L. C. (1984). "Sediment transport: part II: suspended load transport." Journal of Hydraulic Engineering, 110, 1613-1641.

Villard, P. V., Osborne, P. D., and Vincent, C. E. "Influence of wave groups on sand resuspension over bedforms in a large scale wave flume." Proceedings of the 4th International Symposium on Coastal Engineering and Science of Coastal Sediment Processes CS99, New York, 367-376.

Villard, P. V., Osborne, P. D., and Vincent, C. E. (2000). "Influence of wave groups on SSC patterns over vortex ripples." Continental Shelf Research, 20, 2391-2410.

Vincent, C. E., Hanes, D. M., and Bowen, A. J. (1991). "Acoustic measurements of suspended sand on the shoreface and the control of concentration by bed roughness." Marine Geology, 96, 1-18. 